\title{
Flexible Learning in College Physical Education in the Time of a Global Health Crisis and Beyond
}

\author{
Heildenberg C. Dimarucot ${ }^{1,2, *}$, Jerrwin C. Aguinaldo ${ }^{3}$, Elaine Carie A. Andres ${ }^{4}$ \\ ${ }^{1}$ Human Kinetics Department, College of Arts and Sciences, San Beda University, Manila, Philippines \\ ${ }^{2}$ Department of Graduate Studies and Transnational Education, Institute of Education, Far Eastern University, Manila, Philippines \\ ${ }^{3}$ Physical Education Department, De La Salle University, Manila, Philippines \\ ${ }^{4}$ Department of Service Physical Education, Polytechnic University of the Philippines, Manila, Philippines
}

Received July 10, 2021; Revised August 16, 2021; Accepted September 21, 2021

\section{Cite This Paper in the following Citation Styles}

(a): [1] Heildenberg C. Dimarucot, Jerrwin C. Aguinaldo, Elaine Carie A. Andres, "Flexible Learning in College Physical Education in the Time of a Global Health Crisis and Beyond," International Journal of Human Movement and Sports Sciences, Vol. 9, No. 5, pp. 1058 - 1066, 2021. DOI: 10.13189/saj.2021.090528.

(b): Heildenberg C. Dimarucot, Jerrwin C. Aguinaldo, Elaine Carie A. Andres (2021). Flexible Learning in College Physical Education in the Time of a Global Health Crisis and Beyond. International Journal of Human Movement and Sports Sciences, 9(5), 1058 - 1066. DOI: 10.13189/saj.2021.090528.

Copyright $\bigcirc 2021$ by authors, all rights reserved. Authors agree that this article remains permanently open access under the terms of the Creative Commons Attribution License 4.0 International License

\begin{abstract}
Flexible learning has never been more relevant in Physical Education (PE) than during the COVID-19 pandemic as universities continuously provide opportunities to improve students' physical health and address the lack of physical activity among the youth. To understand the importance of flexible learning to the college students in a private university in the Philippines, the extent of the flexibility offered, and the students' satisfaction with it, an online survey and focus group discussions involving college Physical Fitness students were conducted. The significant relationship among the importance of flexibility, the extent of flexibility, and the level of students' satisfaction was also tested. It was revealed that the students found all the flexible learning dimensions vital to them, with the flexibility of time as the most important due to the duality of their roles while studying at home. The students also mentioned that the level of flexibility and the academic and technical support they received benefited them significantly as they became more independent, resilient, resourceful, and critical learners. It was also found that there is a significant relationship among the importance of flexibility, the extent of flexibility, and the level of students' satisfaction. This study could give the higher education institutions feedback on making flexible learning more suitable to the changing needs of the students. Further research on the applicability of flexible learning in other areas of the country and in other disciplines in the academe would give a better
\end{abstract}

perspective on the compatibility of flexible learning in the Philippine university context.

Keywords Flexible Learning, Physical Education, Higher Education, Remote Learning

\section{Introduction}

The World Health Organization has considered the escalating levels of physical inactivity and the diseases that result from it a "pandemic" [1]. Thus, UNESCO emphasized under its Quality Physical Education (QPE) guidelines the need to ensure an accessible and inclusive Physical Education (PE) that "enables adjustments to different needs, ensures that everyone benefits from a commonly agreed level of quality education, and that gives teachers freedom to adapt their working methods to achieve maximum impact and relevance within their specific classroom context." [1].

It is also hoped that through the implementation of QPE, young people will have a sustained motivation to engage in physical activities as a lifelong habit that would not only benefit them physically, but also mentally and socially [1]. Such curriculum flexibility ensures the development of students' physical competence through hands-on applications and exercises on self-regulation 
such as how to cope and act independently in unexpected situations [1].

Learners all over the globe are currently facing a more complex health emergency, the COVID-19 global pandemic. The lockdowns have disrupted peoples' sport and physical activities. As people have been confined in their homes, they may tend to be less physically active, have longer screen time, and suffer from irregular sleep patterns and even more unhealthy diets. These can lead to mental health effects that can aggravate the stress or anxiety as they are away from their peers in school or at work [2].

This global health crisis also has a palpable impact on access to education, especially for vulnerable populations; in the Philippines alone, 32.1 million learners were forced to learn away from their second home and migrate to online learning. Thus, flexible approaches and delivery are typically employed in such situations to cater to the needs of young people until they are ready to return to regular education [3]. It is a huge help that people worldwide have coped with this through online learning resources for students to follow at home and a plethora of fitness demos that proliferated on social media platforms.

The Commission in Higher Education or CHED [4] in the Philippines allowed higher education institutions (HEIs) flexibility in reducing the program requirements, without compromising the attainment of learning outcomes, and employ maximum consideration and leniency for students who have limited access to internet and education due to financial constraints caused by the pandemic. UP College of Education proposed the Emergency Remote Learning Continuity Plan (ERLCP) whose guiding principles are aligned also with UNESCO's QPE's thrusts: compassion, inclusion, and innovation. It advocates for "realistic and sensible combination of flexibilities which makes learning attainable" [5] and a flexible delivery that allows students to enjoy learning on their own pace, unburdened by excessive requirements but not short-changed in terms of quality of learning.

Even before the pandemic, flexible learning has benefited students due to its convenient and accessible learning scheme and the freedom the students should decide on their learning pace, path, and place considering their learning styles and personal circumstances [6], [7]. Thus, students are empowered as they are active creators and sharers of knowledge [8] through synchronous and asynchronous classes. Students can also interact with their teachers and seek for technical support from school staff when needed [6]. Thus, this type of learning also fosters positive relationships [7] that further help students succeed in this kind of environment despite the independence that it promotes. Students are also provided more varied and personalized activities and materials [9] and they enjoy deeper learning of concepts as they are engaged in activities that give them a glimpse of how a real workplace environment looks like and what attitudes their future career expects from them [7]. Flexible online learning was seen to aid in achieving learning outcomes better and to satisfy the learners' needs [6], [7].

However, this pedagogical innovation is not without barriers. While students are given more student agency about their own learning, this method entails assuming greater responsibility [10], [11]. Students can also experience difficulties choosing the best learning strategy and learning space for them, handling a lot of information, and understanding how to approach their school tasks independently [12]. The students' computer literacy skills to thrive in an online learning environment [7] can also be a hindrance as well as issues on students' access to technology also affect their ability to interact with their classmates and teachers [13]. Interestingly, despite the range of choices that the method offers, some still prefer complementing flexible learning with traditional learning methods (face-to-face) [14] or integrating blended learning [15], [7] to maintain close interaction between teachers and students [7].

With all the responses from the education systems to continue learning despite these uncertain times, there is a need to document the field experiences on the value and impact of existing open, distance, and flexible learning (ODFL) approaches to education through careful use of research tools and methodologies [3] because the more flexible the course is does not mean that it is more beneficial for students [16]. It is then important to consider the distance learners' preferences [16] to cater to their needs, especially in these extraordinary times. It is also important to assess the palpability of the flexibility offered and the effectiveness of this method in catering to the students' learning needs, particularly in the Asian and third-world context. Lastly, it is also important to reflect on the sudden changes in the PE model introduced due to the pandemic, learn from shortcomings, and upgrade digitization, hybridization, and accessible education to ensure equity.

Thus, this study assessed the impact of the practices in teaching a Physical Fitness course in flexible mode on the students' education. Specifically, it aimed to identify the importance of the approaches to flexible learning to the students' education, the extent of flexibility they experienced, and the students' level of satisfaction with the flexibility offered by the course. The relationship of the level of importance of flexibility to their extent and satisfaction was also determined. This present study filled in these gaps to contribute to the improvement of PE in the university and in the country not only, in the time of pandemic but even beyond.

\section{Materials and Methods}

This study used the sequential explanatory mixed-method design to identify the students' perception 
on (1) the importance of flexible learning, (2) the extent of flexibility offered based on their experience, and (3) their satisfaction with its implementation. It is also equally important to process the students' qualitative feedback regarding their learning experience during the flexible learning implementation. The data gathering methods and the compliance with ethical standards were reviewed and approved by the Research Committee of the university. The first and second-year college students officially enrolled in the Physical Fitness/Aerobic/Gymnastic and Cardiorespiratory Fitness/Aerobic Training classes during the first semester of Academic Year 2020 - 2021 in San Beda University Manila were purposively selected as the participants of this study. A total of 189 students participated taking up four different courses. They signed a consent form indicating their willingness to implement the new method and to participate in the study.

For nine weeks, the students underwent a PE course that offered flexibility in the following dimensions: time (pace of the course and moments of assessment), content (choice of lessons and exercises), instructional approach (social organization, language, assessments) and resources, and delivery and logistics (academic and technical support, time and place for studying). In the seventh week of their exposure to flexible learning in their PE course, they answered the online questionnaire based on Mason et al.'s [17] research and Collis, Vingerhoets, and Moonen's [18] flexibility dimensions mentioned above. The questionnaire inquired about the importance of the approaches to flexible learning to the students, the extent of the flexibility of the course, and their satisfaction with it. Prior to its distribution, a pre-test was conducted with 35 students from a class that did not participate in the actual survey. The pre-test results were subjected to the Cronbach's alpha reliability test and received an overall value of 0.944 , indicating high internal consistency.

In the eighth week, a focus group discussion (FGD) was also conducted online with the selected students for a more in-depth inquiry on their perceptions on how important, flexible, and satisfying the implementation of flexible learning was for them. A total of 24 students were purposely selected but only 19 participated in the three sessions held. The FGD responses went through content analysis wherein recurring concepts were counted and tabulated and significant themes were identified.

Frequency was used to count the actual response to a specific item in the questionnaire and the mean and standard deviation were used to present the results of each of the Likert scale items. The spearman $r$ coefficient was computed to determine the relationship of level of importance to their extent and satisfaction. The level of significance is at $5 \%$. The Medcalc Statistical software version 20.008 was used to implement statistical calculations. Afterward, the quantitative data were compared with the results of the content analysis of the qualitative responses from the survey and the FGD and became the basis for the recommendations.

\section{Results}

Table 1 shows the quantitative responses on the level of importance of flexible learning among the Physical Education students. The overall mean of 3.45 denotes that the students rated the flexible learning to their education as very important. Specifically, the resulting average of 3.40 also suggests that the students considered their PE course as flexible in terms of time. Moreover, flexibility in the content of the course and the topics was also rated as very important by the students (3.38). On flexibility in instructional approach and resources, the resulting mean of 3.43 also implies that they considered it as very important. Similarly, it was also very important to them that their PE course is flexible in delivery and logistics (3.45).

Looking across all dimensions, flexibility in time and place where the support for students is available got the highest mean of 3.55 and thus identified as the most important. This was followed by the resulting mean of 3.54 for the learning resources and delivery channels. On the other hand, although still very important, the lowest mean is 3.31 , referring to the flexibility in language used in class and in outputs submitted. 
Table 1. Quantitative Responses on the level of Importance of Flexible Learning among College Physical Education Students

\begin{tabular}{|c|c|c|c|}
\hline & Mean & SD & Interpretation \\
\hline Flexibility in Time & 3.40 & 0.68 & Very Important \\
\hline Moments of studying the course & 3.40 & 0.67 & Very Important \\
\hline Pacing of the course & 3.41 & 0.68 & Very Important \\
\hline Moments of assessment & 3.39 & 0.68 & Very Important \\
\hline Flexibility in Content - Content of the course and the topics discusses? & 3.38 & 0.69 & Very Important \\
\hline Flexibility in Instructional Approach and Resources & 3.43 & 0.70 & Very Important \\
\hline Social organization of learning & 3.46 & 0.70 & Very Important \\
\hline Language used in class and in outputs submitted & 3.31 & 0.77 & Very Important \\
\hline Learning resources & 3.54 & 0.64 & Very Important \\
\hline Assignments required for the course & 3.42 & 0.66 & Very Important \\
\hline Flexibility in Delivery and Logistics & 3.52 & 0.65 & Very Important \\
\hline Time and place where the support for students is available & 3.55 & 0.65 & Very Important \\
\hline Method of obtaining support (e.g., via email, chat, landline, etc.) & 3.53 & 0.61 & Very Important \\
\hline Place for studying & 3.47 & 0.67 & Very Important \\
\hline Delivery channels (how the students acquire learning resources) & 3.54 & 0.66 & Very Important \\
\hline Overall Mean & 3.45 & 0.68 & Very Important \\
\hline
\end{tabular}

*1.00 to 1.75 Very Unimportant, 1.76 to 2.5 Unimportant, 2.51 to 3.25 Important, 3.26 to 4.00 Very Important

Table 2. Qualitative Responses in the Survey and in the FGD on the Importance of Flexible Learning

\begin{tabular}{|c|c|c|c|c|c|}
\hline \multirow{2}{*}{ Concept } & \multirow{2}{*}{$\begin{array}{c}\begin{array}{c}\text { Number of } \\
\text { Responses }\end{array} \\
\text { Survey }\end{array}$} & \multicolumn{3}{|c|}{ Number of Responses } & \multirow{2}{*}{$\begin{array}{c}\text { Total of FGD } \\
\text { Responses }\end{array}$} \\
\hline & & FGD 1 & FGD 2 & FGD 3 & \\
\hline Adjustment/adaptation during the pandemic & 21 & 0 & 0 & 2 & 2 \\
\hline Consideration of the professor & 10 & & & & 0 \\
\hline Limitation of space & 6 & & & & 0 \\
\hline Pacing of learning/time management & 35 & 4 & 2 & 2 & 8 \\
\hline Internet connection problem & 23 & & & & 0 \\
\hline Mental health/stress/burn out & 21 & & & & 0 \\
\hline Quality output & 7 & 3 & 2 & 2 & 7 \\
\hline Mastery of the lesson & 2 & & & & 0 \\
\hline Given freedom and options & 4 & 3 & & & 3 \\
\hline Use of gadget/equipment & 3 & & & & 0 \\
\hline Students' personal needs & 1 & 1 & 1 & 2 & 4 \\
\hline Learning capability & 3 & & & & 0 \\
\hline Developing independence & & 1 & & & 1 \\
\hline Freedom in the use of language & & 4 & 3 & 4 & 11 \\
\hline
\end{tabular}

These responses matched the students' qualitative responses in the survey (Table 2) that stated that the above-mentioned flexible dimensions they highly valued helped them in adjusting to the new learning environment brought by the pandemic ( 21 responses) and reduced the academic stress (21 responses) they expected to be even worse without the offered flexibility, especially in terms of time. Moreover, some respondents also shared that flexibility in time was much needed due to the limitations they experienced in their internet connection at home (23 responses). Notably, more students expounded on how important it is for them to be given enough time to finish their tasks at their own pace with 35 survey responses and 8 FGD responses. This ample time also allowed them to produce quality output (7 responses) as they were able to rehearse more and retake their videos if they are not satisfied with their output.

Table 3 shows the quantitative responses on the extent 
of flexibility experienced by the Physical Education students in their course. The overall mean of 3.38 denotes that the students rated the course to be very flexible. Specifically, the resulting average of 3.33 also suggests that students considered the course as very flexible in terms of time. Moreover, flexibility in content of the course and the topics was also rated as very flexible by the students (3.34). On instructional approach and resources, the resulting mean of 3.44 also implies that they consider it as very flexible. Similarly, on delivery and logistic of their course, students also claimed that it was also very flexible. This was also supported by 23 survey respondents who explained how the professor had been very considerate of their circumstances that affect their learning in PE and nine FGD informants who mentioned that their professor had been most of the time available for consultation both online and offline (Table 4). The respondents and FGD participants also shared how they could maximize their space at home (10 responses) whether comprehensive or limited to practice their routine.

Deep diving on the specific items across all dimensions, the most flexible for them is the social organization of learning with a mean of 3.49. Indeed, many of the FGD informants also notably mentioned that they were given a choice to work individually or in pairs for their primary dance performance task (7 responses) as shown in Table 4 . The flexibility of language used in class and in outputs submitted was deemed the next most flexible with a mean of 3.45 .

Table 3. Quantitative Responses on the Extent of Flexible Learning among College Physical Education Students

\begin{tabular}{|c|c|c|c|}
\hline & Mean & SD & Very Flexible \\
\hline Flexibility in Time & 3.33 & 0.60 & Very Flexible \\
\hline Moments of studying the course & 3.34 & 0.58 & Very Flexible \\
\hline Pacing of the course & 3.31 & 0.61 & Very Flexible \\
\hline Moments of assessment & 3.34 & 0.61 & Very Flexible \\
\hline Flexibility in Content- Content of the course and the topics discusses? & 3.34 & 0.63 & Very Flexible \\
\hline Flexibility in Instructional Approach and Resources & 3.44 & 0.60 & Very Flexible \\
\hline Social organization of learning & 3.49 & 0.60 & Very Flexible \\
\hline Language used in class and in outputs submitted & 3.45 & 0.63 & Very Flexible \\
\hline Learning resources & 3.43 & 0.61 & Very Flexible \\
\hline Assignments required for the course & 3.38 & 0.57 & Very Flexible \\
\hline Flexibility in Deliver and Logistics & 3.36 & 0.64 & Very Flexible \\
\hline Time and place where the support for students is available & 3.29 & 0.63 & Very Flexible \\
\hline Method of obtaining support (e.g., via email, chat, landline, etc.) & 3.40 & 0.61 & Very Flexible \\
\hline Place for studying & 3.29 & 0.67 & Very Flexible \\
\hline Delivery channels (how the students acquire learning resources) & 3.40 & 0.63 & Very Flexible \\
\hline Overall Mean & 3.38 & 0.62 & \\
\hline
\end{tabular}

*1.00 to 1.75 Very Inflexible, 1.76 to 2.5 Inflexible, 2.51 to 3.25 Flexible, 3.26 to 4.00 Very Flexible

Table 4. Qualitative Responses in the Survey and in the FGD on the Extent of Flexibility Offered

\begin{tabular}{|c|c|c|c|c|c|}
\hline \multirow{2}{*}{ Concept } & \multirow{2}{*}{$\begin{array}{c}\text { Number of Responses } \\
\text { Survey }\end{array}$} & \multicolumn{3}{|c|}{ Number of Responses } & \multirow{2}{*}{$\begin{array}{c}\text { Total of FGD } \\
\text { Responses }\end{array}$} \\
\hline & & FGD 1 & FGD 2 & FGD 3 & \\
\hline Consideration of the professor & 23 & & & & 0 \\
\hline Flexibility in space & 4 & 3 & 6 & 1 & 10 \\
\hline Enough time to do tasks at their own pace & 12 & & & & 0 \\
\hline Selection and availability of online learning materials & 4 & 1 & 2 & 4 & 7 \\
\hline Ease/comfort of doing tasks & 5 & 1 & 1 & & 2 \\
\hline Given freedom and options & 5 & & & & 0 \\
\hline Given feedback on their output & 1 & & & & 0 \\
\hline Students' personal needs & 2 & & & & 0 \\
\hline Delivery or instruction & 3 & & & & 0 \\
\hline Requirements & 5 & & 1 & & 1 \\
\hline Selection of topics & & 2 & 3 & 2 & 7 \\
\hline Choice of social organization & & 5 & 3 & 2 & 10 \\
\hline Availability of teacher for support online & & 7 & 2 & & 9 \\
\hline
\end{tabular}


Table 5 shows the quantitative responses on the level of satisfaction with the flexible learning experienced by the PE students. The overall mean of 3.41 denotes that the students were very satisfied with their PE course's flexibility. Specifically, the resulting average of 3.43 also suggests that the students were very satisfied with the flexibility in time. This was affirmed by nine survey respondents and six FGD informants who specifically mentioned that the ample time given to them to finish their tasks at their own pace was hugely advantageous for them (Table 6). Likewise, they were also very satisfied with the flexibility in instructional approach and resources (3.41). Similarly, on the flexibility in delivery and logistic of their course, students also claimed that they were very satisfied (3.43).

Noticeably, across all dimensions, the students most enjoyed the high level of comfort that they experienced upon being given a chance to use the language they find convenient in communicating with their professor and classmates (3.49). This dimension was followed by method of obtaining support with a mean of 3.47.

Table 7 shows the relationship among the level of importance of, extent of, and satisfaction with flexible learning from the perspective of the PE students. The resulting $\mathrm{p}$ value of 0.0001 implies that the level of importance is significantly related to their rating on the extent of flexibility and satisfaction. Specifically, importance is strong positively correlated with the extent of flexibility ( $\mathrm{r}=.63)$ and satisfaction $(\mathrm{r}=.60)$. In other words, those who considered flexibility as important aspect on their PE course learning, are also the ones who experienced and appreciated the flexibility offered in their course.

Table 5. Quantitative Responses on the level of Satisfaction with Flexible Learning among College Physical Education Students

\begin{tabular}{|c|c|c|c|}
\hline & Mean & SD & Interpretation \\
\hline Flexibility in Time & 3.37 & 0.65 & Very Satisfied \\
\hline Moments of studying the course & 3.39 & 0.59 & Very Satisfied \\
\hline Pacing of the course & 3.35 & 0.68 & Very Satisfied \\
\hline Moments of assessment & 3.37 & 0.68 & Very Satisfied \\
\hline Flexibility in Content - Content of the course and the topics discusses? & 3.41 & 0.60 & Very Satisfied \\
\hline Flexibility in Instructional Approach and Resources & 3.42 & 0.65 & Very Satisfied \\
\hline Social organization of learning & 3.46 & 0.64 & Very Satisfied \\
\hline Language used in class and in outputs submitted & 3.49 & 0.63 & Very Satisfied \\
\hline Learning resources & 3.45 & 0.62 & Very Satisfied \\
\hline Assignments required for the course & 3.31 & 0.68 & Very Satisfied \\
\hline Flexibility in Deliver and Logistics & 3.43 & 0.65 & Very Satisfied \\
\hline Time and place where the support for students is available & 3.42 & 0.64 & Very Satisfied \\
\hline Method of obtaining support (e.g., via email, chat, landline, etc.) & 3.47 & 0.63 & Very Satisfied \\
\hline Place for studying & 3.40 & 0.68 & Very Satisfied \\
\hline Delivery channels (how the students acquire learning resources) & 3.43 & 0.64 & Very Satisfied \\
\hline Overall Mean & 3.41 & 0.64 & Very Satisfied \\
\hline
\end{tabular}

*1.00 to 1.75 Very Unsatisfied, 1.76 to 2.5 Unsatisfied, 2.51 to 3.25 Satisfied, 3.26 to 4.00 Very Satisfied

Table 6. Qualitative Responses in the Survey and in the FGD on the Satisfaction of the Students with the Flexibility Offered

\begin{tabular}{|c|c|c|c|c|c|}
\hline \multirow{2}{*}{ Concept } & \multirow{2}{*}{$\begin{array}{c}\text { Number of Responses } \\
\text { Survey }\end{array}$} & \multicolumn{3}{|c|}{ Number of Responses } & \multirow{2}{*}{$\begin{array}{c}\text { Total of FGD } \\
\text { Responses }\end{array}$} \\
\hline & & FGD 1 & FGD 2 & FGD 3 & \\
\hline Consideration of the professor & 10 & 1 & & & 1 \\
\hline Enough time to do tasks at their own pace & 9 & & 6 & & 6 \\
\hline Provision of learning materials & 2 & & & & 0 \\
\hline Ease/comfort in doing tasks & 5 & 2 & & 1 & 3 \\
\hline Given freedom and options & 1 & 2 & & 1 & 3 \\
\hline Delivery or instruction & 7 & & & & 0 \\
\hline
\end{tabular}

Table 7. Test of Relationship of Level of Importance to Flexibility and Satisfaction

\begin{tabular}{|c|c|c|c|c|}
\hline Level of importance vs & Spearman $\mathbf{r}$ & Interpretation & p value & Conclusion \\
\hline Level of Flexibility & 0.63 & Strong Positive & 0.0001 & Significant \\
\hline Level of Satisfaction & 0.60 & Strong Positive & 0.0001 & Significant \\
\hline
\end{tabular}




\section{Discussion}

\subsection{Task Performance at Their Own Pace}

It is expected that the students highly value flexibility of time the most among the four dimensions because they are juggling three to four subjects in one cycle (nine weeks; there are two cycles in one semester). While the students think that the PE subject is very flexible in terms of time, it does not mean that the time students spend in studying PE would not affect other subjects. Thus, the students must prioritize the professional or general subjects with more requirements and usually these are the ones also that have greater weight in their grade point average (GPA). When curriculum mapping and plotting of requirements even in just one subject are not done, a ripple effect happens. Other subjects taken by the students could be compromised since they could experience difficulties submitting requirements on time. They may be able to submit for the sake of compliance and completion of the subject, but the quality of learning and output may also suffer.

During the pandemic, it was found that the students work doubly during remote learning as they must fulfill domestic and academic responsibilities while studying at home thus their lack of time for physical activity [19]. Interestingly, the results were the same whether it is a private or a state university as the students have found online learning quite challenging in many ways. Through flexible time, students can decide when the best to study is without being disrupted by family commitments that result in positive impact on the students' learning experiences according to the students, as in McGarry, Theobald, Lewis, and Coyer's study [7].

Another factor that makes flexibility of time very useful and favorable for the students is the fact that all subjects in the university are outcomes-based as mandated by the Commission on Higher Education. Therefore, more performance tasks are given to students instead of objectives tests to demonstrate their mastery of the topics. Performance tasks, obviously, take more time to prepare for and accomplish as they usually require students to develop their higher-order thinking skills such as synthesizing, evaluating, and creating.

\subsection{Student Agency in Learning and Assessment}

The students appreciated that they could choose which among the lessons lined up they would like to study and which tasks are manageable for them, similar to the results in Wanner and Palmer's study [15]. As the students considered their ability, time, and the resources that they have in learning PE, they were given more voice on how they would like to be assessed-something that was not largely practiced pre-pandemic. They became more active receptors and creators of knowledge [8] as they became more critical in judging which of what they learned from other sources can be incorporated in their performance. They were given more opportunities to add routines or steps that they think could improve their performance piece after watching exemplars from the teacher and from other online sources. Thus, it became possible to foster deeper learning [7], claim more ownership of their learning, and develop self-regulation [1] as they fended for themselves in the physical absence of their professor.

Interestingly, unlike in the studies of De Boer and Collis [10] and Celaro, Paladini, Rodrigues, and Assumpcao [11], none of the students mentioned that they felt more burdened upon being held more responsible for their learning under this learning setup. This could be due to the provision of academic and technical support from the school and the right amount flexibility given to the students. While there is flexibility, the students were not given too many options that could just cause more confusion; they were also given some reasonable limitations that remind them that their performance is still bound by some rules, conventions, and standards coming from the professor. After all, higher levels of flexibility do not always result in positive outcomes for the students, especially if the flexibility does not consider students' preferences [16] and capabilities.

\subsection{Resilience amidst Technological, Spatial, and Material Limitations}

Occasional power outages especially when calamities strike and Philippines' internet connection that pales in comparison to most developing countries in Asia [20] affect the students' compliance with requirements as well as their attitude toward online learning [21]. Providing students with ample academic and technical supports through various channels such as official emails (Microsoft Outlook) and the Learning Management System for asynchronous classes proved to be helpful in addressing these limitations. Additionally, more practical and convenient means of communication such as Facebook Messenger, Viber, or Telegram were also widely used to ensure no student is left behind.

Some students also do not also have enough space to study privately and freely since most family members are also working or studying at home. Thus, flexible time and space for studying benefitted them as they were able to comply with their requirements at an opportune time when they could already find a comfortable space for them to perform a task at home. The students could learn to be resilient and judicious as they find ways to perform physical activities no matter how wide or narrow their space is. Performing physical activities at home could be difficult for now due to the pandemic but it is possible.

Lack of resources was also one of the barriers that limit the students' chance to do physical activities during online learning [19]. Movement-based assessments in online 
learning requires at a minimum, a camera, video recorder, and space for exercise. Some students do not have a laptop that is better to use for online learning, and for some who have, they share this with other members of the family. With the provision of both synchronous and asynchronous means of learning and submitting requirements, the students could be resourceful in finding ways to fulfill their tasks with their available resources, without compromising the quality of learning and output.

Lastly, students heavily relied on one-click easy access to information's on the internet. Thus, guided and open of communications between the teachers and students was crucial. Aside from the provided learning materials by the teacher and consultation hours, students were encouraged to find other reliable sources of data such as (1) vlogs, (2) software, (3) information from YouTube, (4) podcasts, and (5) electronic academic subscriptions such as ProQuest, EBSCO, and many others. The availability of diverse learning resources afforded by flexible learning provided opportunities for more in-depth and personalized learning [9] and motivated students to become more independent and strategic when they study.

\section{Conclusions and Recommendations}

As there has been a dearth in studies that further attest to flexible learning's effectiveness and focus on the students' preferences of levels of flexibility, this study gave a more contextualized glimpse of how Filipino university students appraise flexible learning's applicability in the academe's present context. All dimensions of flexible learning were deemed important to the students' education, especially flexibility in time, in both the quantitative and qualitative data gathered. The students also expressed the palpable flexibility in all dimensions, especially in terms of instructional approach and resources, and the benefits they reaped as learning PE differently during the pandemic became more bearable for them. The students were able to cope better with the different stressors brought by the sudden shift to flexible and online learning agency as they made the most out of their learning experience despite the lack of space, material resources, and physical interaction. Since it was found that the relationship among the level of importance, flexibility, and satisfaction was significant, all the flexible dimensions then can be retained and reinforced to make flexible learning even more sensitive to the needs of the students, inclusive, and innovative as what UNESCO's Quality PE's has always aimed for. Specifically, studying the possibility of giving them more flexibility in time and assessments while still fulfilling the requirements of the university could satisfy more students in its next implementation.

Educators who might want to implement flexible learning or modify their existing flexible learning mode may consider rethinking their allocation of time for synchronous and asynchronous learning modality, considering the students' technological capacity, preferences, needs, and competence in the subject. Professors could optimize the synchronous sessions by making them engaging and more collaborative using interactive and user-friendly online platforms so that issues about student engagement in online learning will be lessened or resolved. There is also a need to have a more sustainable program that will help students develop resilience as they will surely face more uncertainties and changes in their life [22], [23] after this pandemic.

As there have been diverse results on the effectiveness of flexible learning across cultures and contexts globally, future researchers may further examine how effective flexible learning was implemented in state universities and colleges in the metro and in the rural areas that have scant resources. It would also be interesting to investigate if the results would be the same or diverse across different fields and disciplines in the academe, considering that they have different content, course requirements, and teaching methods.

\section{Acknowledgements}

The researchers would like to thank the Human Kinetics Department of San Beda University for the initiatives to support the implementation and research on flexible learning during the pandemic. They would also like to acknowledge Mr. Gil P. Soriano, Mr. Alvin George C. Cobar and Mr. Vincent Jasper Alontaga for their generosity of time and effort in engaging in meaningful academic discussions with them that paved the way for a more efficient and ethical data gathering procedure and more informed and in-depth analysis of the data gathered in this study.

\section{REFERENCES}

[1] UNESCO, "Quality Physical Education (QPE): Guidelines for Policy-makers," https://en.unesco.org/inclusivepolicyla b/sites/default/files/learning/document/2017/1/231101E.pd f (accessed July 10, 2021).

[2] UNESCO, "COVID-19 Crisis and Curriculum: Sustaining Quality Outcomes in the Context of Remote Learning". https://unesdoc.unesco.org/ark:/48223/pf0000373273/PDF 1373273eng.pdf.multiW (accessed July 10, 2021).

[3] Creed, C., Morpeth, RL., "Continuity Education in Emergency and Conflict Situations: The Case for Using Open, Distance, and Flexible Learning," Journal of Learning for Development, vol. 1, no. 3, 2014. https://files.eric.ed.gov/fulltext/EJ1106122.pdf.

[4] Commission on Higher Education, "CHED COVID Advisory No. 6". https://ched.gov.ph/wp-content/uploads/ 
CHED-COVID-19-Advisory-No.-6.pdf, (accessed July 10, 2021).

[5] UP College of Education, "Stay Well, Keep Learning: Education Resilience and Learning Continuity in the Time of COVID-19". https://educ.upd.edu.ph/wp-content/upload s/2020/05/UPCED_White-Paper_Education-Resilience-an d-Learning-Continuity_May-21_final_1590037819.pdf (accessed July 10, 2021).

[6] Flexibility through Online Learning. Australian National Training Authority. https://www.ncver.edu.au/_data/asset s/file/0016/10159/flexibility-through-online-learning-885.p df (accessed July 10, 2021).

[7] McGarry BJ, Theobald K, Lewis PA, Coyer F. "Flexible earning Design in Curriculum Delivery Promotes Student Engagement and Develops Metacognitive Learners: An Integrated Review," Nurse Education Today, vol. 35, no. 9, 966-973, 2015. DOI: 10.1016/j.nedt.2015.06.009.

[8] Goode, S., Willis, R., Wolf, J., Harris, A. "Enhancing IS Education with Flexible Teaching and Learning," Journal of Information Systems Education, vol. 18, no. 3, 297-302. 2007. https://aisel.aisnet.org/jise/vol18/iss3/4.

[9] Jonker, H., März, V., Voogt, J. "Curriculum Flexibility in a Blended Curriculum," Australasian Journal of Educational Technology, vol. 36, no. 1, 68-84. 2020. https://doi.org/10.14742/ajet.4926.

[10] de Boer, W., Collis, B., "Flexibility Beyond Time and Place: Stretching and Opening the Course" in A. Szucs' \& E. Wagner (Eds.) "The Quality Dialogue: Integrating Quality Cultures in Flexible, Distance, and e-Learning," Proceedings of the 2003 EDEN Annual Conference, 2003.

[11] Celaro, M., Paladini, E.P., Rodrigues, R., Assumpcao, S. "Quality and Flexibility in Higher Education" in A. Szucs' \& E. Wagner (Eds.) "The Quality Dialogue: Integrating Quality Cultures in Flexible, Distance, and e-Learning: Proceedings of the 2003 EDEN Annual Conference", 2003, https://www.eden-online.org/wp-content/uploads/2016/05/ Annual_2003-Rhodes_Proceedings.pdf.

[12] Gordon, N., "Flexible Pedagogies: Technology-Enhanced Learning," The Higher Education Academy. https://www.heacademy.ac.uk/sites/default/files/resources/ TEL_report_0.pdf (accessed July 10, 2021).

[13] Gunn, C., McCormick, R., Honey, M. "The Challenge of Change: Introducing Flexible Learning into a Traditional Medical and Health Sciences Faculty." https://ascilite.org/conferences/auckland02/proceedings/pa pers/125.pdf (accessed July 10, 2021).
[14] Kehoe, J, Tennant, B., Becker, K., "The Challenge of Flexible and Non-Traditional Learning and Teaching Methods: Best Practice in Every Situation?", Studies in Learning Evaluation Innovation and Development, vol. 1, no. 1, 56-63, 2004.

[15] Wanner, T., Palmer, E., "Personalising Learning: Exploring Student and Teacher Perceptions about Flexible Learning and Assessment in a Flipped University Course," Computers \& Education, vol. 88, 354-369, 2015.

[16] Li, KC., "How Flexible Do Students Prefer their Learning To Be?," Asian Association of Open Universities Journal, vol. 9, no. 1, 35-46., 2014. https://doi.org/10.1108/AAOUJ -09-01-2014-B004.

[17] Mason, C, Holt, D., Augar, N., Samawickrema, G, Palmer, S., Ngo, L., Timberlake, T., Munro, J., Atkinson, K., Bray, T., Fluker, G. "Perspective on the Future of Flexible Education," Deakin University, 2009. http://citeseerx.ist.ps u.edu/viewdoc/download;jsessionid=55C8407FB4413B96 CA70C69D2B6F7DAE?doi=10.1.1.194.2571\&rep=rep1\& type $=$ pdf

[18] Collis, B., Moonen, J., Vingerhoets, J., "Flexibility as a Key Construct in European Training: Experiences from the TeleScopia Project," British Journal of Educational Technology, vol. 28, 199-217, 1997. https://doi.org/10.111 $1 / 1467-8535.00026$.

[19] Puen, D. A. Y., Cobar, A. G. C., Dimarucot, H., "Perceived Barriers to Physical Activity of College Students in Manila, Philippines During the COVID-19 Community Quarantine: An Online Survey," Sport Mont, vol. 19, no. 2, 101-106, 2020. doi: $10.26773 / \mathrm{smj} .210617$.

[20] Salac, R. A., Kim, Y. S. "A Study on the Internet Connectivity in the Philippines," Asia Pacific Journal of Business Review, vol. 1, no. 1, 67-88, 2016. https://doi.org/10.20522/apjbr.2016.1.1.67.

[21] Oducado, R.M., Soriano, G., "Shifting the Education Paradigm Amid the COVID-19 Pandemic: Nursing Students' Attitude to E-Learning," Africa Journal of Nursing and Midwifery, vol. 23, no. 1, 2021. https://doi.org/10.25159/2520-5293/8090.

[22] Ryan, A., Tilbury, D., "Flexible Pedagogies: New Pedagogical Ideas." Flexible Pedagogies: Preparing for the Future Series. https://www.heacademy.ac.uk/sites/default/f iles/resources/npi_report.pdf (accessed July 10, 2021).

[23] Cassidy, A., Fu, G., Valley, W., Lomas, C., Jovel, E., Riseman, A., "Flexible Learning Strategies in First through Fourth-Year Courses," Collected Essays on Learning and Teaching, vol. 9, no. 83, 2016. 10.22329/celt.v9i0.4438. 